\title{
Energetic Use of Landfill Biogas as a Power Energy Source: An Economic Feasibility Study
}

\author{
Alessandro Nunes Costa, Elder Geraldo Domingues, Daywes Pinheiro Neto, Wesley Calixto Pacheco, Aylton \\ José Alves and Liberato Santos \\ Nucleus of Studies and Researches Experimental \& Technological (NExT) \\ Federal Institute of Goiás (IFG) \\ Campus of Goiania - Goias, 74900 , Brazil \\ Phone/Fax number: 0055623327 2769, e-mail: prof.eldergd@gmail.com
}

\begin{abstract}
This paper presents an economic feasibility analysis for power generation from the energetic use of biogas produced in a landfill. Quantifications were made for the methane generated in the landfill, the electric power generation potential, and carbon credits. A cost analysis study and an economic feasibility analysis were conducted for the proposed system, taking two possible scenarios into consideration: with and without selling carbon credits. This paper shows the importance of including carbon credits in economic feasibility studies conducted in landfill projects, as such credits constitute an important source of income for such projects to become more feasible.
\end{abstract}

\section{Key words}

Biogas, carbon credits, electricity, economic feasibility.

\section{Introduction}

Fast economic and populational growths together with excessive product consumption, among other factors, increase both the volume of waste generated by society and the demand for energy. On the other hand, high prices and the possibility of fossil fuel depletion, besides environmental issues, have led society into searching for new renewable energy sources, such as solar, wind and biomass.

The energy use of biogas from landfills is one of the alternatives to generate electricity from biomass. Moreover, such projects contribute, among others, to the reduction of Greenhouse Gases (GHG), possibility of using cogeneration process, increasing the Distributed Generation and for the diversification of the energy matrix [1].

With the approval of the Kyoto Protocol and the creation of the Clean Development Mechanism (CDM), both of which aimed at decreasing GHG generation, there has been greater support in the search for adequate solutions for landfills and effluents. With CDM, developing countries can either reduce their emissions or capture GHG by originating Certified Emission Reductions (CER), also known as carbon credits, which can be negotiated in international markets. CER provide an additional incentive for CDM projects to become more attractive [2].

In this way, in August 2010, the Brazilian Government passed Law No. 12.305/10, which created the National Policy on Solid Residues (NPSR) [3]. One of the main aims of this law is the extinction of Brazilian city dumps by 2014 through the implementation of landfills. This law also includes the adoption, the development, and the improvement of clean technologies, as long as its technical and environmental feasibility has been proved, as a way to minimize the environmental impact. Thus, both the Government and private business must provide solutions and implement adequate techniques to reach sustainable development levels for landfill management.

\section{Methodology}

\section{A. Use of Biogas from Landfill to Produce Electricity}

Final waste disposal is one of the severe problems faced by urban centers throughout the world. The practice of turning areas into landfills still is the most common solution, mainly due to its low cost, easy operation, and great residue absorbing capacity when compared to other forms of final waste disposal. However, the environmental effects must be considered, one of them being the emission of GHG which are generated through the decomposing of organic matter. Methane is one of the gases generated in this process, and it is a fuel that can be used as an energy source [4].

Landfill biogas generation is spontaneous when the compacted waste is not in contact with the open air, which 
allows for the anaerobic process of organic waste fermentation. Biogas can be captured more efficiently with internal drains that can be either vertical or horizontal. Such drains are connected to high-density polyethylene tubes which conduct biogas to the suction and condensing sector, and then send it to be burnt. Thus, to generate electricity, instead of just being burnt in flares, biogas has to be captured, conducted, and treated for its combustion in a Motor-Generator Group (MGG) [5]. Fig. 1 illustrates, in a simplified way, a landfill biogas use facility for electricity generation. The acronym MGG indicates the building that are located the Motor-Generator Group of internal combustion.

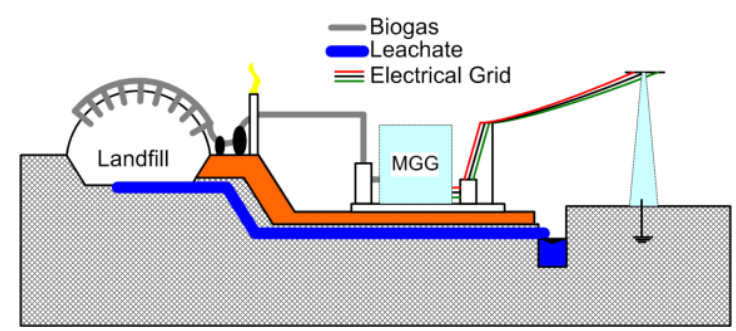

Fig. 1. Landfill biogas production and electricity generation.

\section{B. Basic Aspects of Clean Development Mechanism}

In 1997 several countries signed the Kyoto Protocol, which has ruled since 2005. Through this protocol, developed countries have compromised to reduce their GHG emissions. To help these countries meet their goals, flexibilization mechanisms have been created, such as the CDM, which is the only mechanism that allows for the participation of developing countries $[2,6]$. Through this mechanism, developed countries can buy CER generated by projects in developing countries and use them to either meet their own emission reduction goals, or to invest in CDM projects in these countries, as it is cheaper than implementing such projects in developed countries.

A CDM project activity is considered additional if it reduces anthropic emissions from GHG to levels that are lower to the levels that would have occurred in the absence of the registered CDM project activity. The baseline for a CDM project is a scenario that represents, in a reasonable way, the anthropic emissions of GHG that would occur in the absence of the registered CDM project $\mathrm{CDM}$ project methodology refers to all the processes which are conducted from the beginning of the project writing to the obtaining of CER. A listing of all methodologies can be found at the home page of the United Nations Framework Convention on Climate Change - UNFCCC [6]. In case the desired project activity does not fall into any of the previously approved methodologies, the project developers may opt to submit a new methodology for approval [2].

\section{ACM-0001 Methodology}

According to ENSINAS [5], there are different methods to conduct a theoretic estimate of landfill biogas productions. These methods vary in complexity, and in the amount of needed data, and go from a broad approximation considering only the amount of deposited domestic solid residues - to methods which consider biogas generation kinetics as a function of three important parameters: local weather conditions, soil nutrient concentration, and residue composition. Among these methods, the one which brings estimates closer to reality is the First Order Decay Method, developed by the Intergovernmental Panel on Climate Change - IPCC [2, 5].

This method has gone through a few alterations so as to provide a more exact approximation. This improved mathematical model is currently the most used one in CDM landfill projects, and that is the reason why it was chosen to conduct this study. It is available in the ACM0001 methodology under "Emissions from solid waste disposal sites- Version 06.0.1". The First Order Decay Model considers methane generation by the amount of deposited residue in a year $x$ and the number of subsequent years. As new amounts of residues are deposited each year, the amount of generated methane on a specific year will be equal to the generation of deposited residues in year " $y$ " added to the generation of deposited residues in previous years, which are referenced in year " $y$ " according to Eqn (1).

$$
B E_{C H_{4}, S W D S, y}=A_{G W} \cdot A_{D M} \cdot A_{W D}
$$

where:

$$
\begin{gathered}
A_{G W}=\varphi(1-f) \cdot G W P_{C_{4}}(1-O X) \\
A_{D M}=\frac{16}{12} F \cdot D O C_{f} \cdot M C F \\
A_{W D}=\sum_{x=1}^{y} \sum_{j} W_{j, x} \cdot D O C_{j} \cdot e^{-k_{j}(y-x)} \cdot\left(1-e^{-k_{j}}\right)
\end{gathered}
$$

In which, in Eqn (1), $B E_{C H 4, S W D S, y}$ is the methane emissions generated by waste deposited in the landfill between the beginning of the project activity and the end of year " $y$ " $\left(t C O_{2 e}\right)$. In Eqn (2), $\varphi$ is the correction factor for the model, to account for model uncertainties, $f$ is the fraction of methane captured in the landfill and burnt or used in another form, $G W P_{\mathrm{CH}_{4}}$ is the Global Warming Potential (GWP) for methane, valid through the relevant compromised period and $O X$ is the oxidation factor (reflecting the amount of landfill methane which is oxidized in the soilor in another material which covers the waste). In Eqn (3), $F$ is the fraction of landfill methane gas (volume fraction), $D O C_{f}$ is the fraction of degradable organic carbon $(D O C)$ which may decompose, $M C F$ is the methane correction factor. For the expression Eqn (4) has, $W_{j, x}$ is the amount of type " $j$ " organic wasted deposited in the landfill in a specific year $x$ (tons), $D O C_{j}$ is the fraction of degradable organic carbon (by mass) in type " $j$ " waste and $k_{j}$ is the decay rate for the waste type $j$. The values $j$, $x$ and $y$ are defined as follows: $j$ is the waste type category (index), $x$ is the year of credit period: $x$ goes from the first year of the first credit period $(x=1)$ to the year for which the avoided emissions are calculated $(x=y)$ and $y$ is the year for which methane emissions are calculated. 


\section{Emission Reductions}

According to version 15 of the ACM-0001 methodology, emission reductions in a given year " $y$ " (expressed in $t \mathrm{CO}_{2 e}$ ) can be calculated according to (5).

$$
\begin{gathered}
R E_{y}=M D+E D \\
M D=\left(M D_{p, y}-M D_{B L, y}\right) \cdot G W P_{C H_{4}} \\
E D=E L_{L F G, y} \cdot C E F_{\text {elec }, B L, y}+E T_{L F G, y} \cdot C E F_{\text {ther }, B L, y}
\end{gathered}
$$

Where, $R E_{y}$ is the emission reduction in a given year " $y$ " $\left(t C O_{2 e}\right), M D_{p, y}$ is the amount of methane that would have been burnt or destroyed through the year $\left(t \mathrm{CH}_{4}\right)$ in the project scenario, $M D_{B L, y}$ is the amount of methane that would have been burnt or destroyed throughout the year in the absence of the project due to regulatory or contract demands $\left(\mathrm{tCH}_{4}\right), \mathrm{GWP}_{\mathrm{CH} 4}$ was determined in Eqn (2). The net amount of electricity produced by using biogas is given by $E L_{L F G, y}$. In the absence of project activity, this amount of electricity would have been produced by power plants interconnected into the grid, or by a generation of captive energy, in site or out of the site, based on fossil fuel, during year " $y$ ", in megawatt-hour (MWh). $C E F_{\text {elec, } B L, y}$ is the $\mathrm{CO}_{2}$ emission intensity from the baseline source of displaced electricity, in $t C O_{2 e} / \mathrm{MWh}, E T_{L F G, y}$ is the amount of thermal energy produced using landfill biogas which, in the absence of the project activity, would have been produced by a boiler burning fossil fuel insite or out of the site, during the year " $y$ ", in terajoule (TJ), $C E F_{\text {ther, } B L, y}$ is the $\mathrm{CO}_{2}$ emission intensity of the fuel used by the boiler to generate thermal energy which is displaced by biogas based on the generation of thermal energy, in $\mathrm{CO}_{2 e} / \mathrm{TJ}$

\section{E. Project Emissions}

Project emissions represent the amount of GHG in tons of equivalent $\mathrm{CO}_{2}$ that would be emitted with the implementation of the project. For this calculation, both fugitive emissions and emission emitted by the generator were considered. As the landfill already has a passive ventilation system, it will be necessary to implement a forced ventilation system undertaken by a set of fans with a collect efficiency rate that may reach over $75 \%$ of the total produced biogas [5,8]. Thus, it was considered that $15 \%$ of the total methane emissions would be fugitive. In this way, the other $85 \%$ of the methane generated in the landfill are burnt either in the Otto Cycle motors - thus generating energy, or in flares, according to the following stoichiometric mass balance:

$$
\mathrm{CH}_{4}+2 \mathrm{O}_{2} \rightarrow \mathrm{CO}_{2}+2 \mathrm{H}_{2} \mathrm{O}
$$

Thus, for each ton of $\mathrm{CH}_{4}$ that is burnt we have the generation of 2.75 tons of $\mathrm{CO}_{2}$ that is emitted to the atmosphere. On the other hand, we must take the amount of displaced energy into consideration. Thus, the amount of energy generated with the implementation of the project would be produced by another source, i.e., by an interconnect energy system made of several types of sources. For this situation, the emission factor was calculated according to the "Tool to calculate the emission factor for an electricity system", Version 02.2.0, which is also available in the ACM-0001 methodology, according to (9):

$$
F E=(0.5 \cdot C M)+(0.5 \cdot O M)
$$

Where, $F E$ is the emission factor of the interconnected electric system (ton. $\mathrm{CO}_{2} / \mathrm{MWh}$ ), $\mathrm{CM}$ is the construction margin and $O M$ is the operation margin.

\section{F. Flow Rate of Methane}

To calculate yearly amount of methane, we can use Eqn (10) $[2,5]$.

$$
Q_{\mathrm{CH}_{4}}=\frac{\mathrm{BE}_{\mathrm{CH}_{4}, \mathrm{SWDS}, y}}{d_{\mathrm{CH}_{4}} \cdot G W P_{\mathrm{CH}_{4}}}
$$

In which, $B E_{C H 4, S W D S, y}$ is given by Eqn (1), $Q_{C H 4}$ is the methane flow rate $\left(\mathrm{m}^{3} /\right.$ year $), d_{C H 4}$ is the methane density $\left(t / m^{3}\right), G W P_{C H 4}$ was determined in Eqn (2).

\section{G. Useful Electrical Power}

To calculate the useful electrical power in a given year, we can use Eqn (11) [2,5].

$$
\text { Pot }_{\text {year }}=\frac{Q_{\mathrm{CH}_{4}} \cdot \mathrm{IHP}_{\mathrm{CH}_{4}} \cdot E \cdot \eta}{31,536.000}
$$

In Eqn (11), Pot $_{\text {year }}$ is the useful electrical power available each year $(\mathrm{kW}), Q_{\mathrm{CH} 4}$ is given by Eqn (10), $I H P_{C H 4}$ is the inferior heat power $\left(\mathrm{kJ} / \mathrm{m}^{3} \mathrm{CH}_{4}\right), \mathrm{E}$ is the gas collection efficiency (\%), the value $31,536.000$ is the conversion factor (s/year) and $\eta$ is the electric efficiency $(\%)$.

\section{H. Electric Energy Available for Sale}

To calculate the generated electricity for sale in each year, it is necessary to multiply the useful electrical power by the number of working hours of the MGG, according to Eqn (12).

$$
E E_{D}=\operatorname{Pot}_{\text {year }} \cdot N_{H}
$$

Where, $\mathrm{EE}_{\mathrm{D}}$ is the electricity available for sale in a given year $(\mathrm{kWh}), \mathrm{N}_{\mathrm{H}}$ is the number of working hours of the MGG in one year.

\section{Total Gross Revenue}

The total annual gross revenue will be the sum of the gross revenues from the selling of electricity and from carbon credits. The annual gross revenue from the sale of electricity can be calculated through Eqn (13).

$$
G R_{E E}=E E_{D} \cdot \$_{E E}
$$


Where $G R_{E E}$ is the gross revenue from the sale of electricity in year " $y$ " (in Brazilian Real, or $R \$$ ), $E E_{D}$ is the electrical energy available for sale in a given year $(\mathrm{kWh})$ and $\$_{E E}$ is the price of electric energy (in Brazilian Real, or $R \$)$.

The annual gross revenue from the sale of carbon credits can be calculated according to Eqn (14).

$$
G R_{C C, y}=B E_{y} \cdot \$_{C C, y}
$$

In Eqn (14), $G R_{C C, y}$ gross revenue from carbon credit sales in year " $y$ " $(R \$), B E_{y}$ is the emission reductions in year " $y$ " $\left(t C O_{2 e}\right)$ and $\$_{C C, y}$ is the price of carbon credits in year " $y$ " $(R \$)$.

\section{Results}

The results were obtained in the landfill located in the Middle East area of Goiás State, Brazil. For this case study it is considered the maximum period for carbon credit use of 21 years. Activities would start in the beginning of 2015 and end in December 2035.

The implementation of the landfill occurred at the end of 1999 thus initiating urban waste disposal in the area. The landfill was built in a neighboring area to the municipality's Sewage Treatment Plant (STP), which, besides offering advantages to the treatment of slurry - in case the landfill lagoons cannot handle it, constitutes the implementation of a joint project for biogas use, as the STP generates great quantities of methane.

Fig. 2 presents the estimates for the potential generation of landfill methane in $\mathrm{tCO}_{2 \mathrm{e}}$ for the period of 2000 to 2100 . It also shows methane generation curves for each type of material which constitutes this landfill's waste.

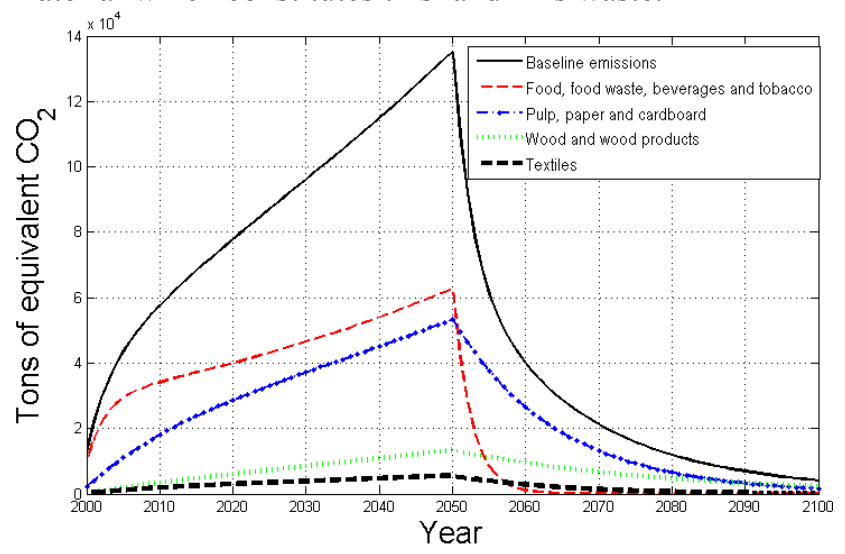

Fig.2. Methane emissions estimates for the landfill.

It is interesting to highlight that after the projected year of closure of the landfill (2050) there will be a continued production of methane which must be used or at least controlled to avoid risks. We should, however, consider the efficacy of the system's collect. Fig.3 shows the total methane amount that can possibly be captured, as well as the emissions that are considered fugitive for the period of 2000 to 2100 .

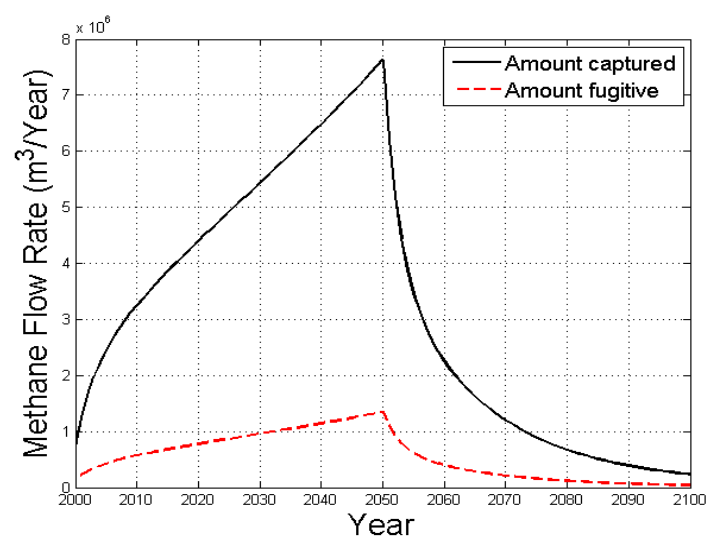

Fig. 3. Captured and fugitive emissions for the landfill.

The average value for the efficiency of the MGG and methane's inferior heat power was considered to be $35 \%$ and $35.53 \mathrm{MJ} / \mathrm{m}^{3}\left(8,500 \mathrm{kcal} / \mathrm{m}^{3}\right)$, respectively [5,8]. Fig. 4 shows the power that can possibly be generated from the year 2000 to 2100, calculated according to Eqn (11).

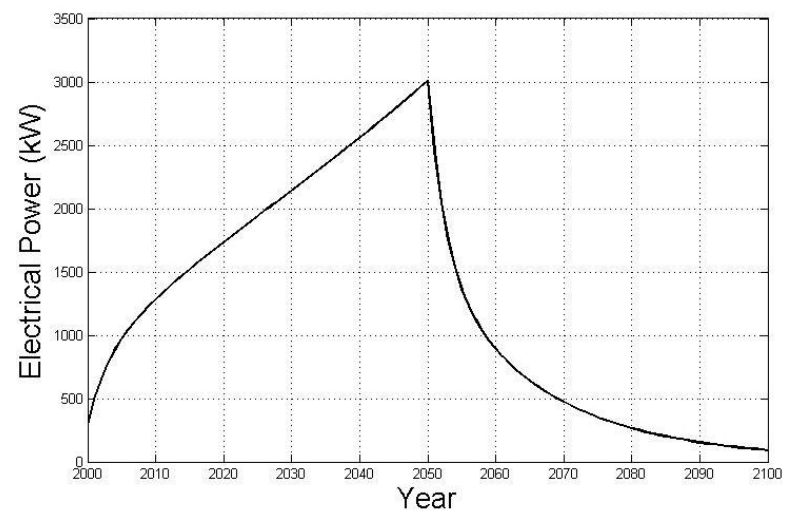

Fig.4 - Estimate of Electrical Power.

It has been confirmed that the best alternative for this business project, considering the costs, is the use of national MGG. It has been used MGG of $330 \mathrm{~kW}$. This type of engine cannot operate on power that is inferior to its capacity. As such, the project would begin with the use of four MGG in 2015. In 2019 it would work with five MGM. In 2027 it would work with six MGM and, in the last year it would work with seven MGG. Due to this limitation and considering that the engines would work 8.560 hours per year, we have calculated the electricity that can possibly be commercialized, as shown in Eqn (12), for the project period, as shown in Fig. 5.

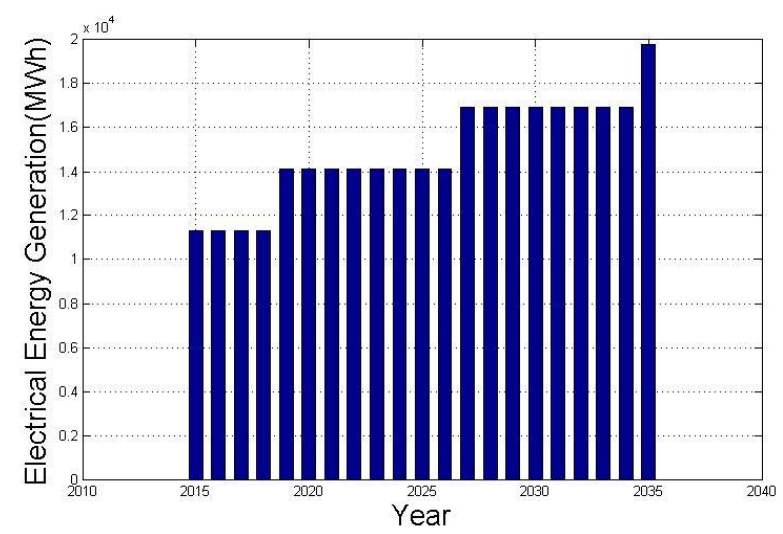

Fig. 5. Electrical Energy generated in the project scenario 
Project emissions represent the amount of GHG in tons of $\mathrm{CO}_{2 \mathrm{e}}$ that would be emitted with the implementation of the project. For this calculation it was considered both fugitive emissions and the ones emitted by the generator. On the other hand, the amount of displaced energy must be considered. As such, the amount of energy generated with the implementation of the project would be produced by another source, i.e., by an interconnected energy system made of several types of sources. The emission factor for the interconnected Brazilian Electric Power System was 0.4322 tCO2/MWh for the year 2013, calculated through Eqn (9), with data being provided by the home page of the Brazilian National Operating System (NOS). This emission factor number was considered as a constant throughout the analyzed period.

Project emissions may be obtained by adding fugitive emissions to the emissions which result from methane combustion and subtracting the emissions which are dislocated by source substitution. With data from both baseline and project scenarios, we can calculate reduced emissions as the difference between baseline emissions and project emissions, as shown in Fig. 6.

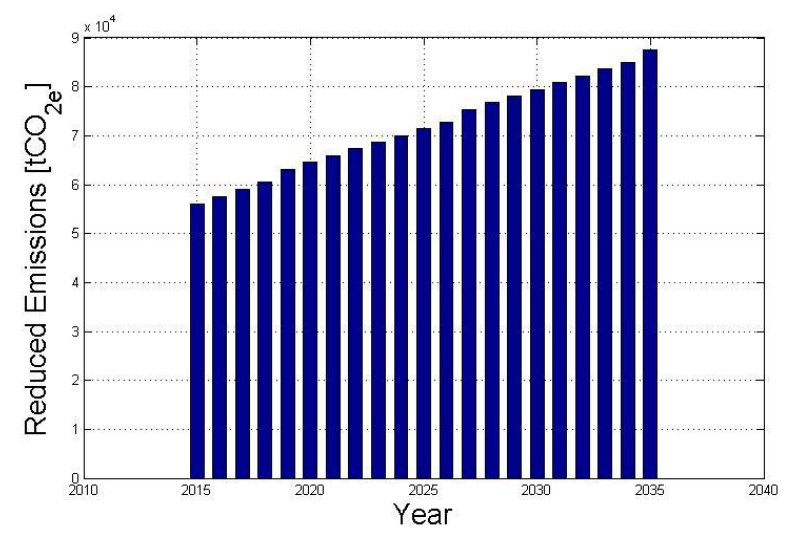

Fig. 6. Reduced Emissions.

To study the economic feasibility of this project it was considered two possible scenarios. The first scenario considers the sale of carbon credits, and the second scenario does not consider this source of revenue.

\section{A. Scenario A: including carbon credit sales}

To generate electricity through landfill biogas and to have the possibility of selling carbon credits it will be necessary to invest in an electric power generating system and in making adjustments to the project so that it fits CDM standards. As the landfill already has a passive ventilation system, it will be necessary to implement a ventilation system that basically consists of a system of vertical and/or horizontal drains which are interconnected to the fan that forces biogas out by means of negative pressure.

It will be necessary to implement an enclosed flare as, in case there is system break down, it should allow for the biogas to burn, in an energy generating system made by MGG, besides a substation. We also considered that electric power will be sold directly to the local distribution company. This company buys energy in two different ways: through contracts, and through auctions. This study considered the most conservative price, which was the one from auction No. 19/2013 regulated by the Brazilian National Electric Power Agency (ANEEL) [7].

The price of CER was considered constant and it was obtained by averaging prices from 2009 to 2013. As such, the considered price for each CER was 8.80 Euros [8].We considered the Euro rate to be 3.0 Brazilian R \$/Euro [9], which can be considered the average price between the second semester 2013 and the first semester 2014. Tables 1 and 2 show the project's fixed and variable costs.

Table I. - Fixed Costs

\begin{tabular}{|l|l|}
\hline \multicolumn{1}{|c|}{ ITEM } & \multicolumn{1}{|c|}{$\begin{array}{c}\text { ANNUAL VALUE (IN } \\
\text { BRAZILIAN R\$) }\end{array}$} \\
\hline $\begin{array}{l}\text { Connection Costs to the } \\
\text { Network }\end{array}$ & $30.000,00$ \\
\hline Operation and Maintenance & $\begin{array}{l}4 \% \text { of the investment in } \\
\text { energy generating equipment }\end{array}$ \\
\hline Administrative Expenses & $\begin{array}{l}2 \% \text { of the investment in } \\
\text { energy generating equipment }\end{array}$ \\
\hline $\begin{array}{l}\text { Connection Costs to the } \\
\text { Network }\end{array}$ & $30.000,00$ \\
\hline Operation and Maintenance & $\begin{array}{l}4 \% \text { of the investment in } \\
\text { energy generating equipment }\end{array}$ \\
\hline
\end{tabular}

Table II. - Variable Costs

\begin{tabular}{|l|l|}
\hline \multicolumn{1}{|c|}{ ITEM } & \multicolumn{1}{c|}{ VALUE (IN BRAZILIAN R\$) } \\
\hline Purification $\mathrm{H}_{2} \mathrm{O}$ & $0,0138 \mathrm{R} \$ / \mathrm{m} 3$ \\
\hline Purification $\mathrm{H}_{2} \mathrm{~S} /$ Siloxane & $0,0138 \mathrm{R} \$ / \mathrm{m} 3$ \\
\hline Purification $\mathrm{CO}_{2}$ & $0,0138 \mathrm{R} \$ / \mathrm{m} 3$ \\
\hline Low Compression & $690 \mathrm{R} \$ / \mathrm{m} 3 / \mathrm{h}$ \\
\hline
\end{tabular}

With the collected data, it was made accounting projections, and it was calculated cash flow in order to obtain the project's Net Present Value (NPV). For this analysis, we considered a Minimum Acceptable Rate of Return (MARR) of $12 \%$ per year. Table 3 shows the results.

Table III. - NVP (case A)

\begin{tabular}{|l|l|}
\hline \multicolumn{1}{|c|}{ ITEM } & \multicolumn{1}{c|}{ VALUE (IN BRAZILIAN R\$) } \\
\hline NVP of Revenues & $\mathrm{R} \$ 13.914 .889,73$ \\
\hline NVP of Investmensts & $-\mathrm{R} \$ 4.085 .600,00$ \\
\hline NVP of equipment sales & $\mathrm{R} \$ 849.600,00$ \\
\hline Project's NVP & $\mathrm{R} \$ 10.678 .889,73$ \\
\hline
\end{tabular}

The IRR for this investment was $41 \%$ per year, and the payback will occur in the year 2018 , i.e., in the $4^{\text {th }}$ year of the project.

\section{B. Scenario B:not including carbon credit sales}

By not including carbon credit sales, results were showed in Table IV. The IRR for this investment was $17 \%$ per year, which is a higher than the estimated MARR, and the payback will occur in the year 2026, i.e., last year of the project. As such, we confirmed that the project has little economic feasibility if carbon credits are not sold. 
Tables V and VI show a summary of the values used for the economic viability analysis of this project.

Table IV. - NVP (case B)

\begin{tabular}{|l|l|}
\hline \multicolumn{1}{|c|}{ ITEM } & \multicolumn{1}{c|}{ VALUE (IN BRAZILIAN R\$) } \\
\hline NVP of Revenues & $\mathrm{R} \$ 5.603 .220,85$ \\
\hline NVP of Investments & $-\mathrm{R} \$ 4.085 .600,00$ \\
\hline NVP of equipment sales & $\mathrm{R} \$ 849.600,00$ \\
\hline Project's NVP & $\mathrm{R} \$ 2.367 .220,85$ \\
\hline
\end{tabular}

Table V. - Parameters used in the project (Part 1)

\begin{tabular}{|c|c|}
\hline PARAMETER & VALUE \\
\hline Implementation of the landfill & Dec/1999 \\
\hline Year of closure of the landfill & 2050 \\
\hline Rate of waste generation & $0,76 \mathrm{~kg} /$ person/day \\
\hline Population growth rate & $1,51 \%$ per year \\
\hline Collection rate of urban waste & $100 \%$ \\
\hline Rate biogas collection & $85 \%$ \\
\hline Inferior Calorific Power of Methane & $8.500 \mathrm{kcal} / \mathrm{m}^{3}$ \\
\hline Efficiency of motor- generator group & $35 \%$ \\
\hline Hours of working of GMG & $8560 \mathrm{~h} /$ year \\
\hline $\begin{array}{l}\text { Emission Factor of National } \\
\text { Interconected System }\end{array}$ & 0,4322 tCO2/MWh \\
\hline Duration of the project & 21 years \\
\hline Start of project & Jan/2015 \\
\hline End of project & Dec/2035 \\
\hline Energy Price & $\mathrm{R} \$ 126,18$ \\
\hline Price of Carbon Credits & $\mathrm{R} \$ 26,40 /$ ton $\mathrm{CO}_{2 \mathrm{e}}$ \\
\hline Social Integration Program & $0,65 \%$ of Revenue \\
\hline $\begin{array}{l}\text { Contribution to Social Security } \\
\text { Financing }\end{array}$ & $3 \%$ of Revenue \\
\hline Administration Costs & $\begin{array}{l}2 \% \text { of initial } \\
\text { investment }\end{array}$ \\
\hline Maintenance and Operation Costs & $\begin{array}{l}4 \% \text { of the value of the } \\
\text { equipment per year }\end{array}$ \\
\hline $\begin{array}{l}\text { Connection to the Distribution Net } \\
\text { Cost }\end{array}$ & $\mathrm{R} \$ 30.000,00$ \\
\hline Cost of Purification & $0,414 \mathrm{R} \$ / \mathrm{m} 3$ \\
\hline Cost Compression & $690 \mathrm{R} \$ / \mathrm{m} 3 / \mathrm{h}$ \\
\hline Social Contribution over Net Profit & $8 \%$ \\
\hline Depreciation & 10 year (linear) \\
\hline Minimal Atractiveness Rate & $12 \%$ \\
\hline$\varphi$ & 0.75 \\
\hline$f$ & 0 \\
\hline$G W P_{\mathrm{CH}_{4}}$ & 25 \\
\hline$O X$ & 0.1 \\
\hline$F$ & 0.5 \\
\hline$D O C_{f}$ & 0.5 \\
\hline$M C F$ & 1.0 \\
\hline Density of methane & $0,7167 \mathrm{~kg} / \mathrm{m}^{3}$ \\
\hline Electrical Power of each MGG & $330 \mathrm{~kW}$ \\
\hline
\end{tabular}

Table VI. - Parameters used in the project (Part 2)

\begin{tabular}{|l|l|l|l|}
\hline \multicolumn{1}{|c|}{ TYPE OF WATE (j) } & $\begin{array}{c}\text { GRAVIMETRIC } \\
\text { COMPOSITION } \\
(\%)\end{array}$ & $\begin{array}{c}\text { DOCj } \\
(\% \text { WET } \\
\text { BASE) }\end{array}$ & $\mathrm{Kj}$ \\
\hline $\begin{array}{l}\text { Wood and wood } \\
\text { products }\end{array}$ & 5 & 43 & 0.035 \\
\hline $\begin{array}{l}\text { Pulp, paper and } \\
\text { cardboard }\end{array}$ & 17 & 40 & 0.07 \\
\hline $\begin{array}{l}\text { Food waste, beverages } \\
\text { and tobacco }\end{array}$ & 45 & 15 & 0.40 \\
\hline Textiles & 3 & 24 & 0.07 \\
\hline Gardening waste & 0 & 20 & 0.17 \\
\hline
\end{tabular}

\section{Conclusion}

Kyoto Protocol's Clean Development Mechanism represents an opportunity to promote sustainable development, as it makes fund-raising more attractive for this type of project. Two possible scenarios were considered for this economic feasibility analysis: with and without selling carbon credits. Results show that the two possibilities are economically feasible, as both NVP resulted positive. However, the no-carbon credit sale scenario presents little economic feasibility, as payback will only occur in $12^{\text {th }}$ of the project and the internal rate return was $17 \%$ per year, which is higher than the considered minimum attractive rate of return of $12 \%$ per year. This study presented landfill biogas production for a 100-year time span, and maximum biogas production will occur at landfill closure time. As such, it is important to consider energetic use beyond the determined period for this case study, as the analyzed years do not correspond to the period in which there is greater biogas production.

\section{Acknowledgement}

The authors would like to thank both the Environmental Department of the Municipality and the landfill managers for providing the necessary data to undertake this research project.

\section{References}

[1] SALOMON, K. R., LORA, E. E. S. Estimate of the electric energy generating potential for different sources of biogas in Brazil, Biomass and Bioenergy, Volume 33, Issue 9, September 2009, Pages 1101-1107.

[2] United Nations Framework Convention on Climate Change. Clean Development Mechanism Methodology Booklet, Fifth Edition, November 2013, ISBN 978-92-9219-118-4.

[3] BRAZIL. Law No. 12.305/10 that creates the National Policy on Solid Residues (NPSR). Official Gazette of the Federative Republic of Brazil, Executive Power, Brasilia, DF, Brazil, August 3, 2010, Section 1, page 2.

[4] ZAMORANO M. at. Alli. Study of the energy potential of the biogas produced by an urban waste landfill in Southern Spain, Renewable and Sustainable Energy Reviews, Vol. 11, Issue 5, Pages 909-922, June 2007.

[5] ENSINAS, A. V. Study of the generation of biogas in the Delta landfill. Thesis, State University of Campinas, Campinas, SP, Brazil, 2003 (in Portuguese).

[6] UNFCCC Methodology ACM0001, "Consolidated baseline methodology for landfill gas project activities", 2013.

[7] ANEEL, National Agency of Electricity.Auction No. 019/2013 - A3. Auction to purchase electrical energy from new generation projects. Available at: < www.aneel.gov.br >. Accessed 22 Jun. 2014.

[8] REUTERS ECOWIN- Prices of approved CDM allowances from 2009 to 2012. Available at :<http://www.reutersecowin.com>. Accessed:15 dec. 2013.

[9] UOL ECONOMIA. The dollar. Available at: $<$ http://economia.uol.com.br/cotacoes/cambio/euro-uniaoeuropeia-principal.jhtm>. Accessed: 22 jun. 2014. 